Gut, 1987, 28, S1, 275-279

\title{
Absorptive capacity of the transplanted small bowel
}

\author{
P SCHROEDER, EDELTZ, J SEIFERT, F SANDFORTH, AND A THIEDE \\ From the Department of General Surgery, University of Kiel, Department of Internal Medicine, Freie \\ Universität Berlin, Federal Republic of Germany
}

SUMMARY Small bowel transplantation (SBT) has been carried out in man in several cases without success, because immunologic problems were unsolved. In experimental SBT a 'two step' model was developed, which enables long term observation of immunologic phenomena. In this model the graft is in a heterotopic position to the recipient's own small bowel. After 35 days the recipient's own bowel is removed and replaced by the graft, now in orthotopic position and again in contact with luminal chymus. To investigate functional and morphological changes, which result from the procedure, the resorption of glucose and water was measured in syngeneic transplanted rats by an in vivo recirculation system and the mucosa was evaluated three dimensionally. The graft mucosa showed a significant reduction in villus height, crypt length and villus surface and a corresponding decrease in glucose and water absorption during heterotopic position. If the graft came into the orthotopic position, the mucosa did regenerate which was expressed by the significant longer crypts of the graft compared with those of the controls, although the graft's villus height and surface are still smaller. Glucose and water absorption increased and were higher in orthotopic transplanted animals, when absorption was expressed per unit intestinal length. The results indicate that in the 'two step' model of SBT the absorption of water and glucose is influenced to such an extent, that recovery is possible after three weeks, thus enabling orthotopic SBT. This almost complete recovery of the mucosa is further evidence of the regeneratory capacity of the small bowel, which enables clinical small bowel transplantation.

Small bowel transplantation (SBT) in man has been performed on several occasions, but it has been unsuccessful from the standpoint of survival of the patient. ${ }^{1}$ The reason for this failure lies in unsolved immunological problems related especially to the lymphatic tissue of the intestine.

Several models for small bowel transplantation have been designed to investigate these problems. We must distinguish between three different types of transplantation. (1) Heterotopic auxiliary transplantation, in which the recipient's intestine remains in situ and the graft is transplanted as an adjunct to the recipient's organ, with the ileum of the graft attached to the recipient's ileum with an end-to-side anastomosis. (2) Orthotopic transplantation, in which the recipient's intestine is removed and replaced by the transplanted organ. (3) A combination of the two types, in which the organ is first transplanted heterotopically, then at a later date, the recipient's intestine is removed, and the graft is placed in orthotopic position. ${ }^{2}$

We use the last method, because the auxiliary graft has the advantage that it allows long term observation of immunological phenomena, and the animal can survive even if the graft is rejected. Certain phenomena that might influence the absorptive capacity of the graft, such as intestinal wall oedema and intraluminal fluid loss, do not have such disastrous effect. If the grafts were transplanted directly into orthotopic position, they would lead to the death of the animal. It has been shown that the lymphatic vessels, which were interrupted during explantation of the bowel, become revascularised in the recipient. ${ }^{1}$ This is the basis for the restitution of absorptive and transport functions during the period in which the small bowel is in heterotopic position. During this period the graft is cut off from chymus and should develop mucosal atrophy with a corresponding decrease in the absorptive parameters of the mucosa ${ }^{3}$ assuming the principle of the effects of 'luminal nutrition' to the intestinal mucosa holds.

The trauma of this intestinal wall-ischaemia, oedema and the missing stimulation of the mucosa by chymus could lead to a functional loss in secretion 
and absorption. Furthermore, monosaccharide absorption has been used by some authors as an indicator of graft rejection. ${ }^{4,5}$ The presumed damage of the mucosa and the fact that the relationship between glucose absorption and villus architecture is known, ${ }^{6}$ encouraged us to investigate the extent of morphological and functional alterations in the mucosa of the small bowel resulting from the different steps of the surgical procedure.

\section{Methods}

SURGICAL PROCEDURE

We used the above mentioned procedure of heterotopic and orthotopic SBT. ${ }^{2}$ All surgical procedures, including preparations for perfusion, were carried out under ether anaesthesia.

\section{ANIMALS}

Group 1 consisted of six male LEW rats who were subjected to heterotopic SBT and on day 35 post operatively to the perfusion experiment. Each graft was compared with the recipient's own intestine. In group 2 six male LEW rats were also subjected to heterotopic SBT. On day 35 post operatively the recipient's bowel was replaced with the graft, which was then in orthotopic position. Five male LEW rats (group 3) served as untreated controls. The animals in groups 2 and 3 underwent the perfusion experiment on day 21 after the second operation - that is, 56 days after heterotopic SBT.

\section{PERFUSION EXPERIMENT}

For in vivo perfusion in a recirculation system we used the apparatus of Sheff and Smyth, ${ }^{7}$ which was modified by Menge et al. ${ }^{6}$ A Krebs-Henseleit solution ${ }^{8}$ containing $20 \mathrm{mmol} \mathrm{D}$-glucose was used for perfusion. The solution was either perfused through the graft and the recipient's own intestine (heterotopic SBT). Or it was perfused through the grafted intestine (orthotopic SBT) and the controls simultaneously. Perfusion was carried out over a period of 45 minutes under steady state conditions in conscious animals.

\section{MOR PHOMETRIC STUDIES}

Tissue was taken from jejunum and ileum of graft and control intestine at a distance of $2 \mathrm{~cm}$ from the anastomoses. The villi were microdissected and villus parameters were measured and calculated. ${ }^{9,10}$

STATISTICAL ANALYSIS

The Student's $t$ test was used for statistical evaluation.

\section{Results}

During the period of heterotopic SBT, in which the recipient's own small bowel is responsible for absorption, the body weight of the animals increased, as in the unoperated group. After orthotopic positioning of the graft the body weight decreased during the 21 days between step 2 and the perfusion experiment, but the decrease was not significant. After long term observation the body weight of the animals subjected to orthotopic SBT increased.

\section{HETEROTOPIC SBT}

The morphometric evaluation of the mucosa showed a significant difference in villus height between graft and recipient's intestine in both jejunum and ileum $(p<0.05)$. A corresponding difference in crypt length and a decrease in villus length and width could also be demonstrated on day 35 after heterotopic SBT. Compared with the individual morphometric parameters, the calculated villus surface is significantly reduced after heterotopic SBT $(p<0.05)$ (Fig. 1).

The in vivo absorption of $\mathrm{D}$-glucose and water, expressed per unit of length of the intestine, is significantly reduced in the heterotopic graft, as compared with the recipient's own intestine on day 35 $(p<0.05)$. If absorption is expressed per unit of surface area, the absorptive capacity for D-glucose within the heterotopic graft is increased by a factor of 1.9 and that for water by a factor of 1.4 (Fig. 2). The absorptive capacity, expressed per unit intestinal length, is decreased by a factor of 0.7 (D-glucose) and 0.5 (water) within the heterotopic graft.

\section{ORTHOTOPIC SBT}

In the jejunum the villi did increase in size, but did not reach the values for those in the control intestine. The crypts were significantly longer than in the controls $(p<0.05)$. The other villus parameters (length and width) also increased. In the ileum the villi were significantly higher, and the crypts significantly longer than in the controls $(p<0.05)$. When the villous surface was calculated, the jejunal villi reached $70 \%$ of the control villi, and those of the ileal villi were $16 \%$ larger than in the controls (Fig. 1).

Twenty one days after orthotopic SBT the absorption of both D-glucose $(p<0.05)$ and water $(p<$ 0.05 ) had clearly increased and was significantly higher than in the controls, if absorption is expressed in $\mu \mathrm{mol}$ or ml per unit of length of the intestine per minute (Fig. 2). Expressed in terms of villous surface, the absorptive capacity for D-glucose increased by a factor of 1.6 and that for water by a factor of 1.4 in the graft, as compared with the controls. The absorptive capacity, expressed per unit intestinal length, is increased by a factor of 1.3 for both D-glucose and water in the graft. 


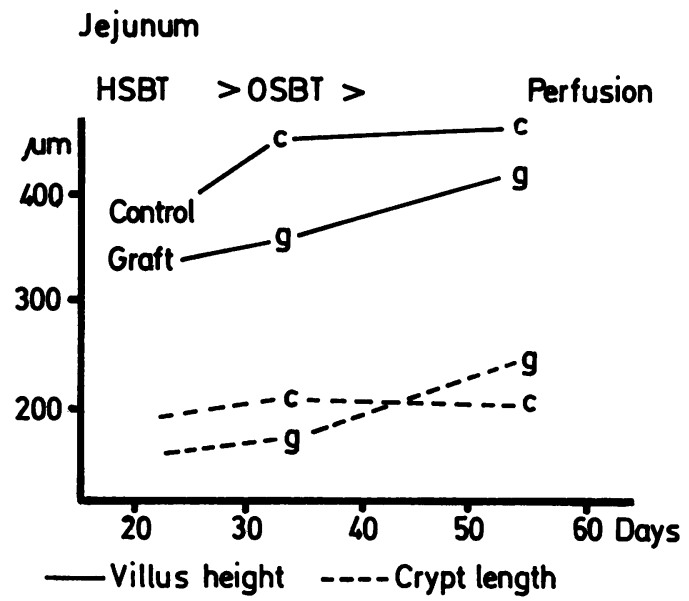

Ileum

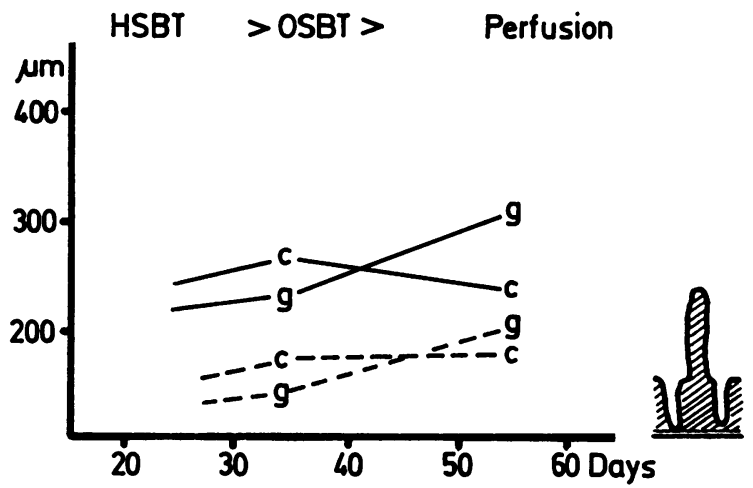

Fig. 1 Morphometric results

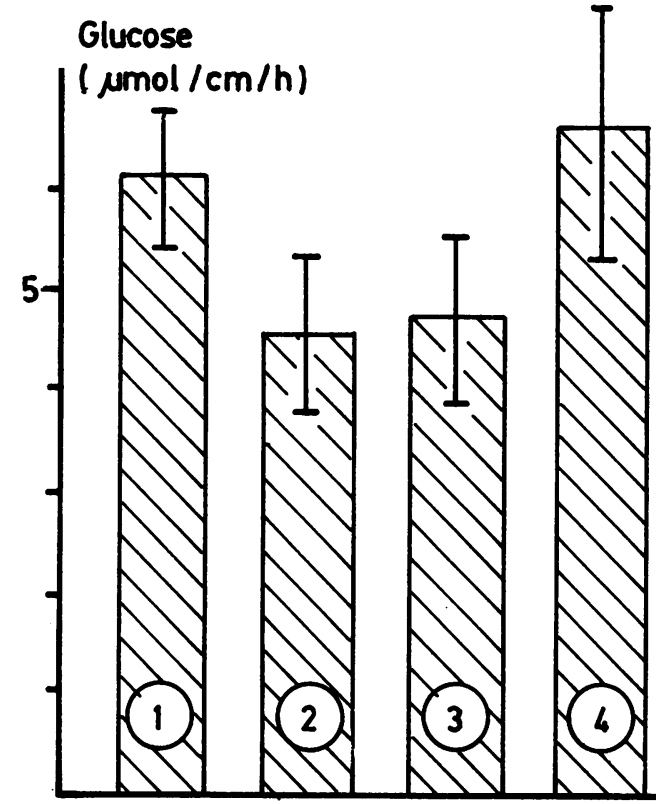

Col $1+2$ after HSBT ( $n=635 d p$ op)

Col 1-recipient's own intestine

Col 2-graft-intestine HSBT.

$1: 2=p<0.05 \quad 3: 4=p<0.05$

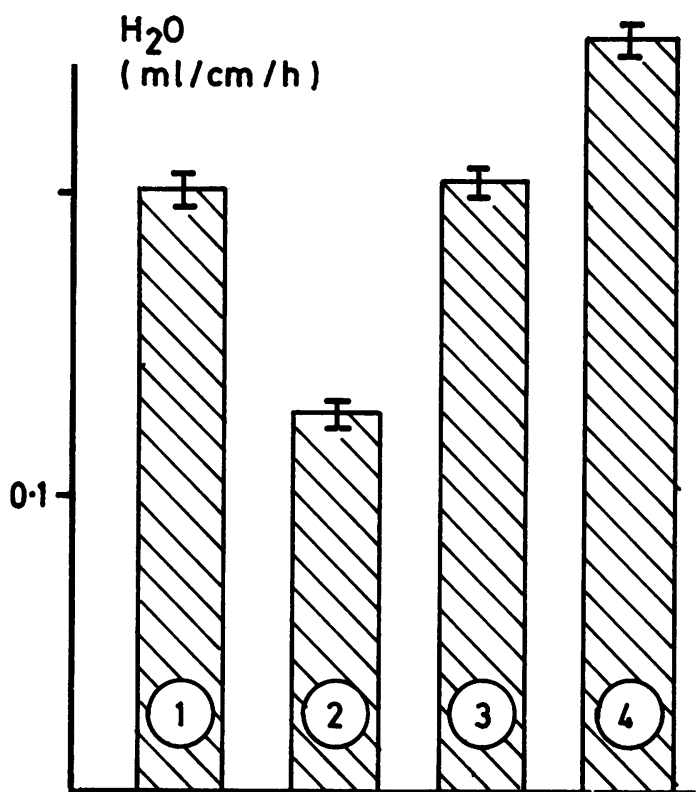

Col $3+4$ after OSBT ( $n=6 / 3, n=5 / 456 d p$ op)

Col 3 -control intestine (non operated rats)

Col 4 -graft-intestine OSBT

$1: 2=p<0.05 \quad 3: 4=p<0.02$ Student-t-test

Fig. 2 Absorption results 


\section{Discussion}

During transplantation the small intestine undergoes a certain period of cold ischaemia, and during heterotopic SBT the graft is in a similar position as a selfemptying blind loop. Menge et al. ${ }^{3,11}$ and Robinson et al. ${ }^{12}$ were able to show in several blind loop experiments that being cut off from chymus leads to severe atrophy of the small bowel with a corresponding decrease in absorptive function. Earlier experiments had shown that autotransplantation of intestinal loops had no effect on the absorption of Dglucose, amino acids and fatty acids, ${ }^{13,1,14}$ although in this kind of transplantation denervation and interruption of lymphatic vessels also occur. ${ }^{1}$ By clamping mesenteric vessels for 30 minutes, Robinson and Mirkovitch showed a typical loss of transport capacity after ischaemia and a total morphological and functional recovery after mesenteric reperfusion of the clamped vessels. ${ }^{15}$

Similar to blind loop experiments, our morphometric results show that the crypt and villus compartments are atrophied after the period of heterotopic SBT. Corresponding to this atrophy, a decrease in absorption of water and D-glucose can be shown. Because in principle the architecture of the mucosa is intact, such factors as ischaemia and denervation or disconnection of lymphatic vessels do not seem to play an important role in absorption, even in the atrophic mucosa of the heterotopically transplanted intestine. Furthermore, ice cold ischaemia and storage of the graft during the first transplantation step can avoid severe damage to the mucosa by reducing cell metabolism, in contrast with the studies of Robinson and Mirkovitch, who worked under conditions of warm ischaemia. ${ }^{15}$ Twenty one days after orthotopic SBT we found that the mucosal compartments had recovered to a great extent. The crypts in jejunum and ileum and the villi in the ileum were longer than in controls, which indicates that chymus which could now pass through the graft, has a hyperregeneratory effect. Menge et al. ${ }^{16}$ were also able to show in selfemptying loops that when the loops were shifted back into the luminal passage there was a total restitution of morphology and function. Corresponding to this morphological restitution of the graft, D-glucose and water absorption is significantly increased in the orthotopically transplanted graft, compared with the controls - in a kind of overshooting phenomenon, expressed in terms of absorption/length of intestine.

If absorption is expressed in terms of units of mucosal surface area, the absorptive capacity for Dglucose shows only a slight trend to normalisation in orthotopically transplanted animals, compared with heterotopic grafting which is expressed in the de- crease of the calculated absorption factor. This is in accordance with the clinical shape of the animals and with the restituted absorption after orthotopic SBT, although a slight mucosal atrophy can still be shown 56 days after orthotopic SBT. The explanation for this can be found in the data of Menge et al. ${ }^{17}$ who showed a decrease in alanine uptake, expressed per unit of surface area. Expressed as a function of a single enterocyte or per unit of intestinal length, however, it increased. This means that the villous surface is not as important for absorption as the functional status of the absorbing cells is in a hyperregeneration status. Thus we have an explanation for the increased body weight and the good clinical shape of the animals after orthotopic SBT, although the mucosa is still atrophied eight weeks after transplantation.

Our results indicate that the 'two step' model of small bowel transplantation is suitable for clinical application and that the absorption of monosaccharides and water is influenced to such an extent that recovery is possible after three weeks, thus enabling orthotopic SBT. This is further evidence for a regeneratory capacity, which is the prerequisite for clinical SBT.

We are indepted to Heidi Twisselmann und Matthias Gundlach for skilful technical assistance.

\section{References}

1 Hardy MA, Iga $\mathrm{CH}$, Can $\mathrm{H}$. Intestinal transplantation. Laboratory experience and clinical consequences. In: Thiede A, Deltz E, Engemann R, Hamelmann H, eds Microsurgical models in rats for transplantation research. Berlin: Springer, 1985; 337-46.

2 Deltz E, Thiede A. Microsurgical technique for smallintestinal transplantation. In: Thiede A, Deltz E, Engemann R, Hamelmann H, eds. Microsurgical models in rats for transplantation research. Berlin: Springer, $1985 ; 51-5$.

3 Menge $\mathrm{H}$, Werner $\mathrm{H}$, Lorenz-Meyer $\mathrm{H}$, Riecken EO. The nutritive effect of glucose on the structure and function of jejunal self-emptying blind loops in the rat. Gut 1975; 16: 462-7.

4 Billiar TR, Garberoglio C, Schraut WH. Maltose absorption as an indicator of small-intestinal allograft rejection. J Surg Res 1984; 37: 75-82.

5 Nordgren $S$, Cohen Z, Greenberg GR, Langer $B$. Monitoring of rejection and absorption studies after small-bowel transplantation in the dog model. In: Thiede A, Deltz E, Engemann R, Hamelmann H, eds. Microsurgical models in rats for transplantation research. Berlin: Springer, $1985 ; 131-4$.

6 Menge H, Bloch R, Schaumlöffel E, Riecken EO. Transportstudien, morphologische Untersuchungen zum Verhalten der Dünndarmschleimhaut im operativ ausgeschalteten Jejunalabschnitt der Ratte. Z Ges Exp Med 1970; 153: 74-90. 
7 Sheff MF, Smyth DH. An apparatus for the study of in vivo intestinal absorption in the rat. $J$ Physiol 1955; 128: 67.

8 Krebs HA, Henseleit K. Untersuchungen über die Harnstoffbildung im Tierkörper. Hoppe-Seylers Z Physiol Chem 1932; 210: 33-66.

9 Clarke RM. Mucosal architecture and epithelial cell production rate in the small intestine of the albino rat. J Anat 1970; 107: 519-29.

10 Lorenz-Meyer H, Köhn R, Riecken EO. Vergleich verschiedener morphometrischer Methoden zur Erfassung der Schleimhautoberfläche des Rattendünndarms und deren Beziehung zur Funktion. Histochemistry 1976; 49: 123-9.

11 Menge H, Robinson JWL, Schroeder P. Functional and structural correlations in the atrophic mucosa of selfemptying blind loops of rat small intestine. $J$ Physiol 1978; 280 : 33-4.

12 Robinson JWL, Menge H, Schroeder P, Riecken EO, van Melle G. Structural and functional correlations in the atrophic mucosa of self-emptying blind loops of rat jejunum. J Clin Invest 1980; 10: 393-9.

13 Cohen WB, Hardy MA, Quint J, State D. Absorptive function in canine jejunal autografts and allografts. Surgery 1969; 65: 440-6.

14 Stamford WP, Hardy MA. Fatty acid absorption in jejunal autograft and allograft. Surgery 1974; 75: 496-502.

15 Robinson JWL, Mirkovitch V. The recovery of junction and microcirculation in small intestinal loops following ischaemia. Gut 1972; 13: 784.

16 Menge H, Bloch R, Lorenz-Meyer H, Riecken EO. Morphologie und Funktion isoperistaltischer, ausgeschalteter Jejunalschlingen nach Rückverlegung in die Dünndarmpassage. Res Exp Med (Berl) 1973; 161: 133-40.

17 Menge H, Sepúlveda FV, Smith AW. Cellular adaptation of amino acid transport following intestinal resection in the rat. $J$ Physiol 1983; 334: 213-23. 